\title{
Clinical evaluation of upper incisors retraction frictionless system depending on mini-screw
}

\begin{abstract}
Objectives: The aim of the study was a computed and clinical evaluation of upper incisors frictionless retraction system using mini implants.

Methods: Three dimensions mechanical analysis has been done by Software for model geometry ((Anasys ver. 11)). The retraction system consisted of mini implant as a point of support and a rigid orthodontic arch wire for the anterior teeth stabilization that extended $2 \mathrm{~mm}$ distally and $6 \mathrm{~mm}$ gingivally from bracket's slot to formed Power arm as a point to apply the retraction force. The two models of springs that had been made of TMA and Elgiloy Alloys, as a source of the orthodontics force had been used. The results of finite elements analysis were applied at 27 class II division 1 malocclusion patients (13male, 14 female). The patients divided into two groups. Applying a triangle spring at group one with $4 \mathrm{~mm}$ activation and applying a circle spring at group two with $2 \mathrm{~mm}$ activation.

Results: The movement in group 1 was the partly Controlled tipping by translation with the ratio of the apex movement to edge movement $(0.38 \pm 0.42)$, but in group 2 the movement was the controlled tipping by translation with relation $(0.69 \pm 0.51)$ and no significant difference was between groups $(p=0.93)$ Conclusion: The suggested frictionless retraction system produced good control of the upper incisor movement
\end{abstract}

Volume I Issue 2 - 2014

\author{
Mahmoud AL Suleiman,' Feras Baba,' Ayman \\ Suliman,' Omar Swas ${ }^{2}$ \\ 'Department of Orthodontics, Faculty of Dentistry, University \\ of Aleppo, Syria \\ ${ }^{2}$ Department of Aeronautical Engineering, Faculty of Mechanical \\ Engineering, University of Aleppo, Syria
}

Correspondence: Mahmoud AL-Suleiman, Department of Orthodontics, Faculty of Dentistry, University of Aleppo, Aleppo, Syria,Tel 967000000000,Email alsuleimanm@gmail.com

Received: May 09, 2014 | Published: May 30, 2014

\section{Introduction}

Recent researches carried out to avoid the complications of incisors retraction by conventional techniques such as losing of the anchorage, control torquing and no bodily movement. ${ }^{1-4}$ Absolute anchorage can be achieved by using orthodontic implants. ${ }^{5}$ The Mini-screws were used for incisors retraction without losing anchorage in comparison to the traditional method retraction ${ }^{6,7}$ and the optimal treatment can complete without patient's cooperation, and without anchorage losing. ${ }^{6,89}$ The control of the orthodontic movement depends on the relationship between force vector and the center of resistance. When the force vector passes through the center of resistance, the movement should be bodily, However, and will be tipping when it does not pass through the center of resistance, that affected by force magnitude and distance between force vector and the center of resistance. ${ }^{3,10}$ The centers of resistance of central incisor and lateral incisor were 9.6, 8.6 $\mathrm{mm}$ from bracket's slot respectively. ${ }^{11,12}$ In other studies of four upper incisors was $77 \%$ from the apex of root $^{13}$ and $5 \mathrm{~mm}$ gingivally form alveolar crest ${ }^{14}$ and was at $7 \mathrm{~mm}$ gingivally from center alveolar crest for all anterior teeth, or $9-10 \mathrm{~mm}$ gingivally and $7 \mathrm{~mm}$ distally from the center of the lateral incisor bracket. ${ }^{15,16}$ Power Arm's length affects on controlling the incisors retraction movement, when mini-screw used as supporting point. If arm length increased, torque movement increased and intrusion movement decreased. ${ }^{17}$ 8-10mm height recommended for torque movement and $6-8 \mathrm{~mm}$ for tipping controlled movement. ${ }^{18}$

Moments and reaction of mechanical system can canceled by one couple system, that is practical application of determinate force system as cantilever spring, and moments stay constant. Consequently, no friction, 3D movement control, safe time and efforts will be gained. ${ }^{4,9,20}$ Park et al. ${ }^{21}$ used positioners for retain the teeth and lever arm for force application, they concluded that frictionless retraction was benefit for movement control

Updhyay et al. ${ }^{22}$ found that incisors retraction by skeletal anchorage was more speed than incisors retraction by traditional anchorage. Choy et al. ${ }^{23}$ used statically determinate frictionless retraction system for upper incisors retraction; they concluded that there was no extrusion or tipping movement. Park et al. ${ }^{24}$ used segmental retraction; they observed that the force vector passed through resistance center that resulted in a controlled movement.

\section{Objectives}

The aims of this study were a clinical evaluation of computerized designed system for upper incisors frictionless retraction depending on mini-screw.

\section{Materials and methods}

The retraction system consisted of:

Mini-screw was the support point. A rigid orthodontic arch wire used for the anterior teeth stabilization; that extended $2 \mathrm{~mm}$ distally, and 6-8 $\mathrm{mm}$ gingivally to form a Power arm that considered as a point of force application. Self drilling mini-screw of Titanium Alloy (Ti6AL4V) (Forestadent- Germany), 9mm length, $1.6 \mathrm{~mm}$ diameter, $2 \mathrm{~mm}$ neck (Cross head \& Cross hole $\# 0.8 \mathrm{~mm}$ ) used, that inserted at $8 \mathrm{~mm}$ above main wire between first molar and second premolar in mucogingival junction under (after initial leveling and aligning) according to Sung. ${ }^{25,26}$

Two models of spring created as the source of forces that extended from mini-screw to a power arm. Every model was made of TMA and Elgiloy alloys; the first: a Triangle loop, with the inner side length was $5 \mathrm{~mm}, 0.016^{*} 0.022$ Inch cross section (Figure 1) and the second: a circle loop, with the diameter was $5 \mathrm{~mm}$ too; $0.016 * 0.022 \mathrm{Inch}$ crosses section (Figure 2). Software for model geometry ((Anasys version 11)) was used for three dimensions mechanical analysis to determine the optimal form of the springs according to the load/ deflection rate. Orthodontic Bands (0.018 inch) (RMO), Pre adjusted appliance Brackets (0.018 Inch) from (Forestadent- Germany) applied. 0.016×0.022 Inch TMA wire, $0.016 \times 0.022$ Inch Elgiloy Blue 
wire (RMO) and 0.018* 0.025Inch, SS arch (Universal form) (IOSUSA) were used (Figure $3 \& 4$ ).

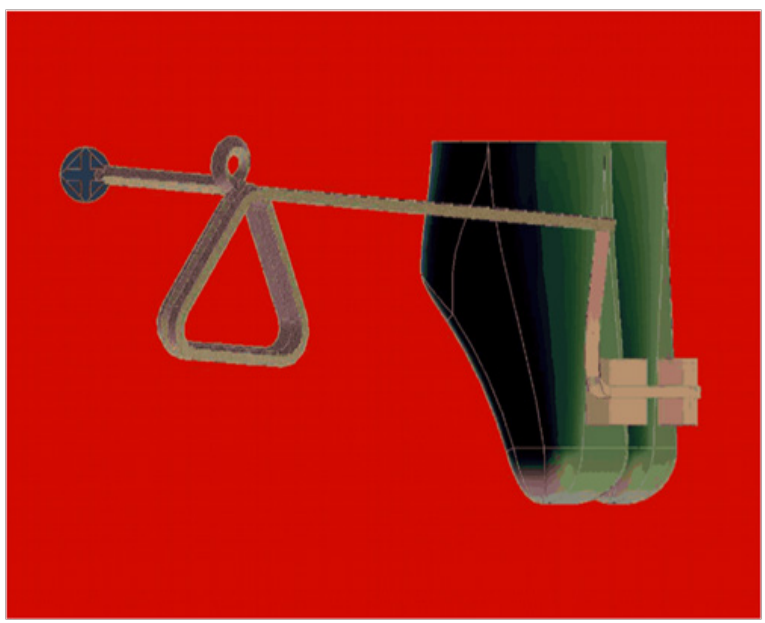

Figure I Finite element model of retraction system (consist of triangle spring, power arm, miniscrew).

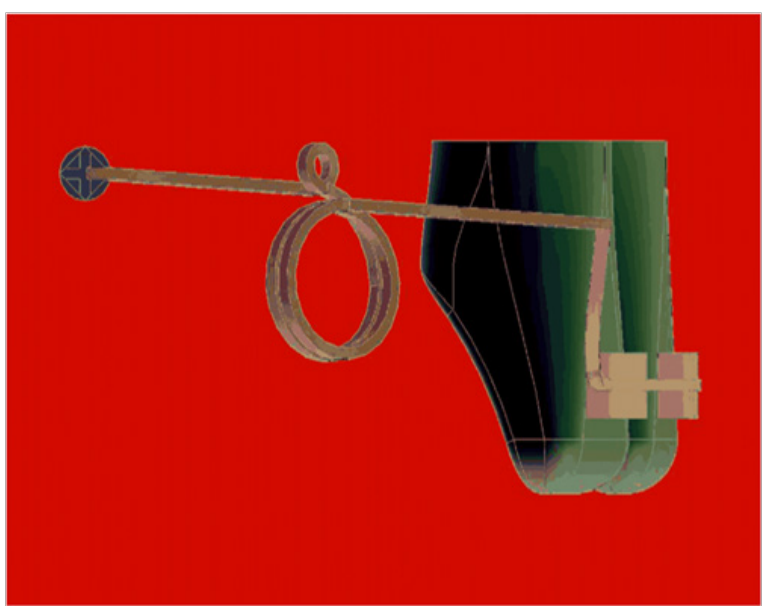

Figure 2 Finite element model of retraction system (consist of circle spring, power arm, miniscrew).

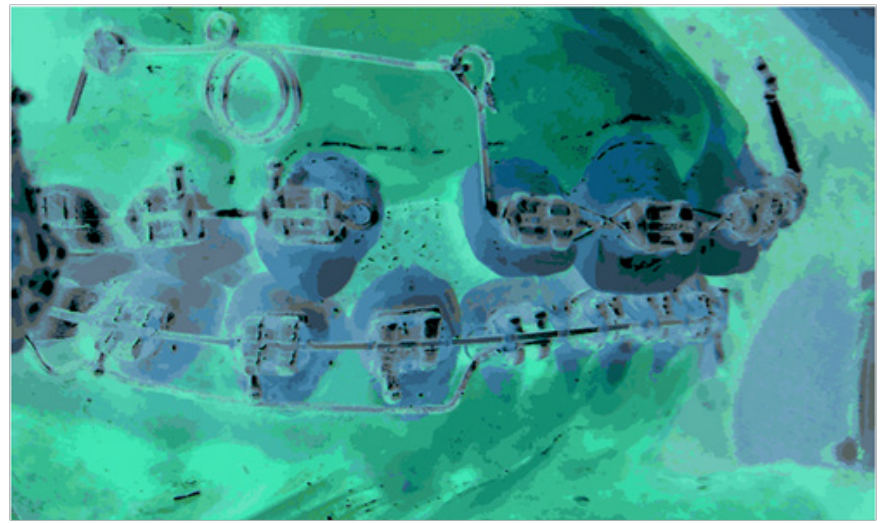

Figure 3 Retraction frictionless system depending on mini-screw shows spring, power arm, location of miniscrew.

The conclusion of finite elements analysis of springs, were applied at 27 patients (13 male, 14 female), who had class II division 1 malocclusion and the upper first premolar extracted, which required maximum anchorage for upper incisors retraction (Table1). All the participated patients signed a consent form and approved the follow up of treatment, and then Subjects randomly divided into two groups. TPA and $0.016^{*} 0.022$ Inch cross section SS wire used for stability of posterior segments. $100 \mathrm{~g}$ of force applied on each side, the springs were activated every 40 days. Retraction stopped when overjet (2.5$3 \mathrm{~mm}$ ) had achieved.

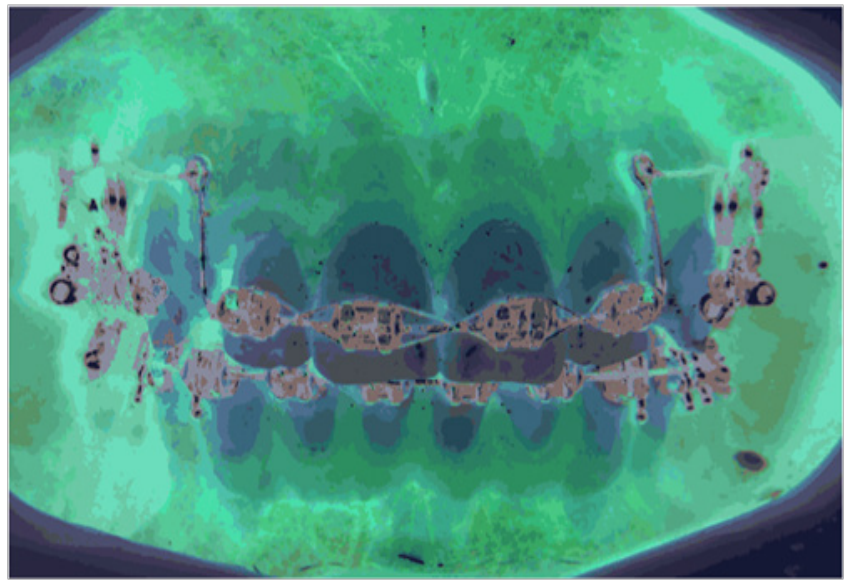

Figure 4 Stability of anterior section $\left(0.018^{*} 0.025\right.$ inch SS wire for horizontal bar and $8 \mathrm{~mm}$ height for Power arm (group I, 2).

Lateral cephalometric radiographs carried out at three times, $\mathrm{T}_{0}$ before retraction, $\mathrm{T}_{1}$ after two months of retraction and $\mathrm{T} 2$ after finishing. The reference lines, used to evaluate the changes in position of Upper incisors, were the SpP line as the $\mathrm{x}$-axis, and the line perpendicular to it through Ptm (pterygomaxillary point) as the $y$-axis, These reference lines used for local superimposition between two times of retraction.

Evaluation retraction movement carried out by:

1. Six parameters measured to observe the movement of upper incisors retraction $\left(\mathrm{T}_{0}-\mathrm{T}_{1}\right)$ and $\left(\mathrm{T}_{0}-\mathrm{T}_{2}\right)$ (Table 2$)$.

2. The point of intersection of pre and post retraction time long axes of central incisor determined as the center of rotation according to Dincer et al. ${ }^{27}$ by local superimposition between two times (T0 \& $\left.\mathrm{T}_{1}\right)$-(T0 \& $\left.\mathrm{T}_{2}\right)$. The location of the CRo was measured as; 0 point: the root apex before retraction, a positive value: CRo value above 0 point, negative value: CRo value below 0 point, $\infty$ : Standard division of CRo mean additive to the maximum value of CRo $(\infty$ were few values and they were outliers that shifted the mean value.

3. The type of movement explained according to UPadhyay et al. ${ }^{22}$ by apex movement to edge movement ratio, $<0$ : uncontrolled tipping (negative value) $=0$ : controlled tipping; $>0$ : controlled tipping to bodily movement (positive value); $=1$ : bodily movement; and $<1$ : root movement (positive value).

$15 \%$ cephalometric radiographs of three stages $\left(\mathrm{T}_{0}, \mathrm{~T}_{1}\right.$, and $\left.\mathrm{T}_{2}\right)$ were randomly selected to return the measurements by one examiner twice at, a 4-week interval and another examiner and Cronbach's Alpha was used for Reliability. The data analyzed by SPSS 17 Using independent sample. (T-test) to compare between two groups, Paired sample (T-Test) to compare treatment changes in group $1 \& 2$ after emphasized the standard distributed of parameters by AndersonDarling test. 
Table I Description of sample

\begin{tabular}{lllllll}
\hline & Patient & Age & Overjet & Spring & Activation & $\begin{array}{l}\text { Load- deflection } \\
\text { Rate }\end{array}$ \\
\hline Group I & 14 (7male-7female) & $19.1 \pm 2.1$ & $7.2 \pm 1.4 \mathrm{~mm}$ & Triangle (TMA Alloy) & $4 \mathrm{~mm}$ & $26.315 \mathrm{~g}$ \\
Group 2 & $13(7$ male-6female) & $19.4 \pm 3.8$ & $7.5 \pm 1.7 \mathrm{~mm}$ & Circle (TMA Alloy) & $2 \mathrm{~mm}$ & 47.504 \\
\hline
\end{tabular}

Table 2 Variable of incisors retraction

\begin{tabular}{ll}
\hline Edge $I / X(\mathrm{~mm})$ \& Apex $I / X(\mathrm{~mm})$ & Vertical movement of central incisors \\
Edge $I / Y(\mathrm{~mm})$ \& Apex $I / Y(\mathrm{~mm})$ & Horizontal movement of central incisors \\
$\mathrm{I} / \mathrm{SpP}(\theta)$ & Angle of central incisors axis and SpP plane \\
Over jet $(\mathrm{mm})$ & Distance between baccul of lower \& upper incisor
\end{tabular}

\section{Results}

Finite element study

The load/ deflection rate of Elgiloy alloy spring was bigger than TMA alloy spring and had reverse correlation with Length of wire, (One loop, Double loop, and double loop-one helix). $8 \mathrm{~mm}$ height of Power arm was the better to reach the translation movement (Table 3). Moreover, concluded that:

1. TMA alloy spring had specified the low load-deflection rate. The load-deflection rate of TMA Alloy triangle spring (double loopone helix) was $26.315 \mathrm{~g} / \mathrm{mm}$ (Figure 1), and The load-deflection rate of TMA alloy Circle spring (double loop-one helix) was $47.504 \mathrm{~g} / \mathrm{mm}$ (Figure 5).

2. $0.018 * 0.025$-Inch cross section SS alloy wire of $8 \mathrm{~mm}$ height of the Power arm should provide the better conditions to make a translation movement; horizontal bar of power arm should be formed as smile shape for opposition of transverse deformation of power arm (Figure 6, Table 3-5).

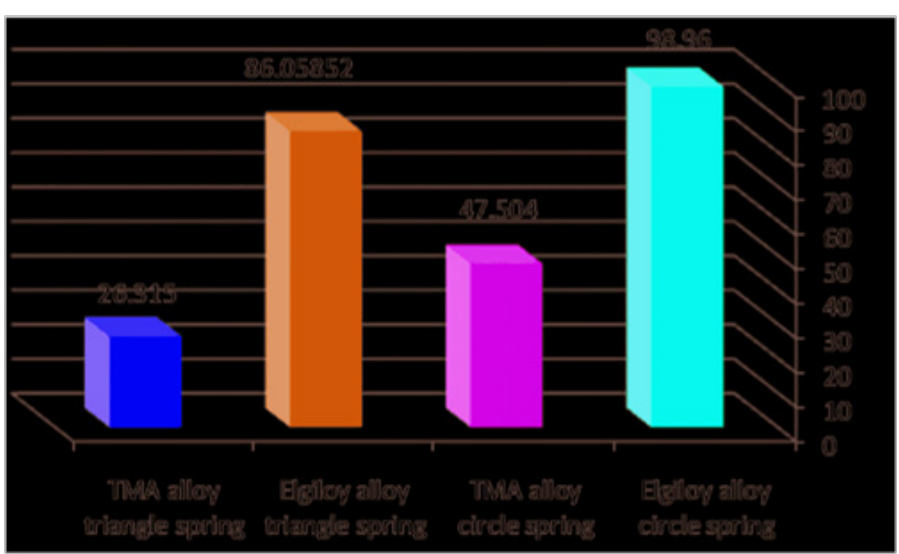

Figure 5 Load/deflection rate of designed triangle, circle spring (Double loopone helix) for two alloys.

\section{Results of clinical study}

The reliability mean of viability was 0.964 in $\left(T_{0}, T_{1}\right.$, and $\left.T_{2}\right)$. The speed of retraction of groupland group 2 was $1.03 \pm 0.32 \mathrm{~mm} / \mathrm{mo}$, $0.842 \pm 0.169 \mathrm{~mm} / \mathrm{mo}$ respectively and no significant difference was between groups, $p=0.076$. No significant difference was between two group's means of apex and edge of upper incisors movement (Table $4)$.

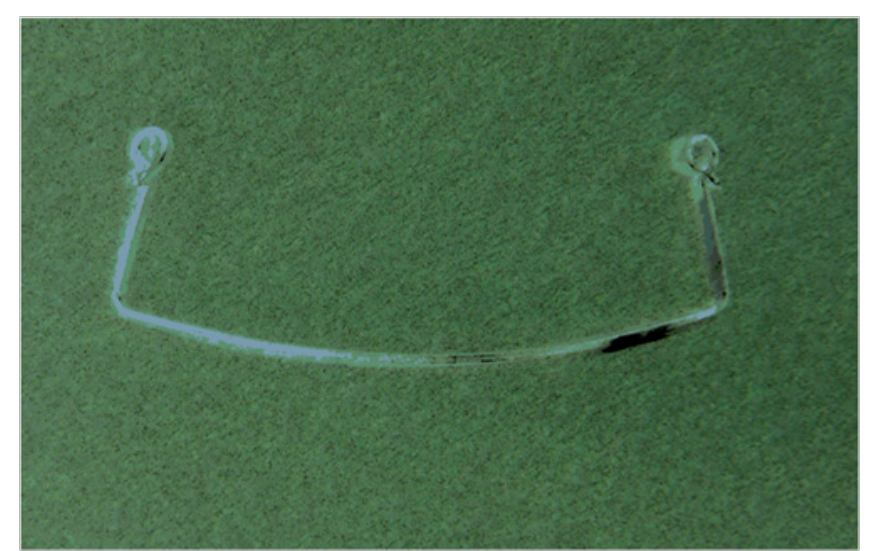

Figure 6 Smile shape of power arm.

\section{The center of Rotation (Cr.O)}

Multi values of location of the center of rotation were between negative, positive and infinite values in both groups at stage $\left(\mathrm{T}_{0}-\mathrm{T}_{1}\right)$ $\&\left(\mathrm{~T}_{0}-\mathrm{T}_{2}\right)$ (Table 5, Figure 7). No significant difference was between groups at stage $\left(\mathrm{T}_{0}-\mathrm{T}_{1}\right)$ and stage $\left(\mathrm{T}_{0}-\mathrm{T}_{2}\right)$; Significant difference was between stages $\left(T_{0} T_{1}\right) \&\left(T_{0} T_{2}\right)$ in each group (Table 6 , Figure 8$)$.

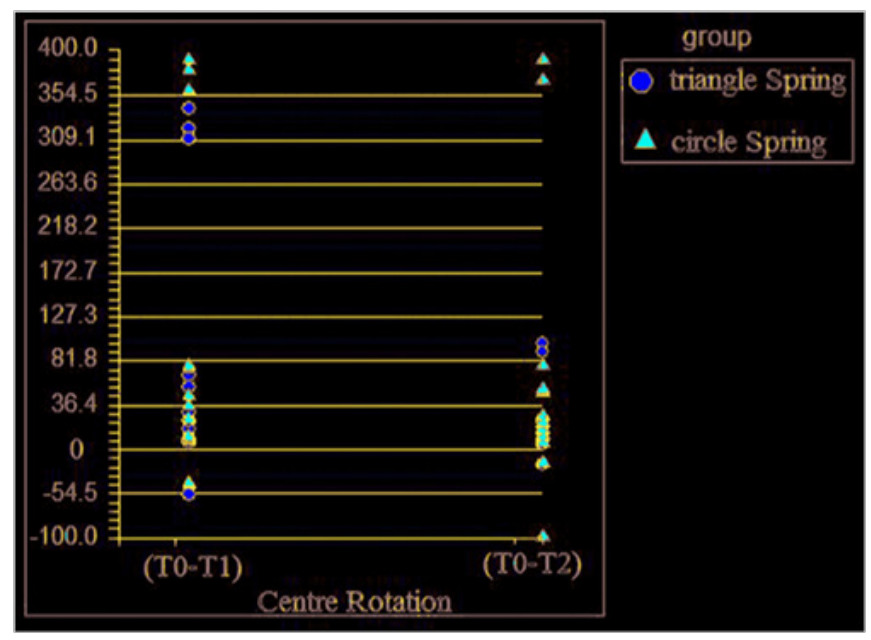

Figure 7 Scatter plot of centre rotation of both groups and two stages. 


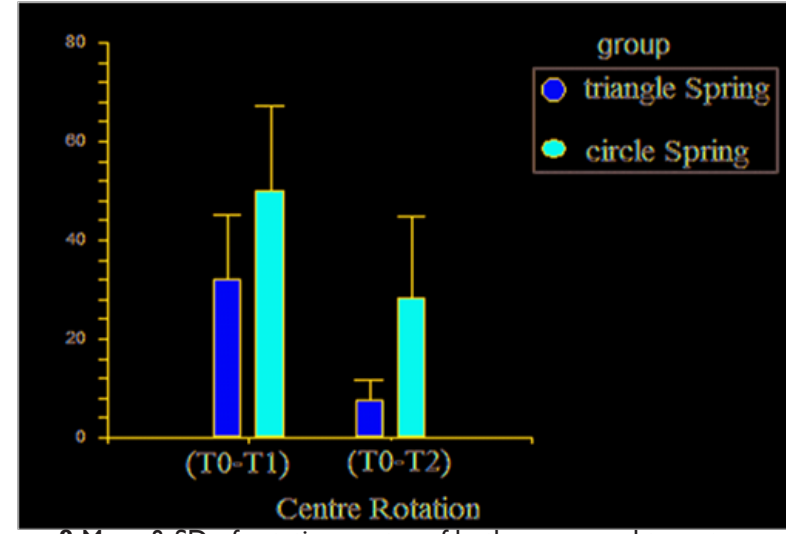

Figure 8 Mean \& SD of rotation centre of both groups and two stages.

\section{Type of movement}

Different types of movement were recorded between groups in both stages $\left(\mathrm{T}_{0}-\mathrm{T}_{1}\right)$ and $\left(\mathrm{T}_{0}-\mathrm{T}_{2}\right)$ according to proposed formula (Uncontrolled tipping, Controlled tipping, Controlled tipping to bodily, Bodily and Torque movement) (Figure 9,10). Partly controlled tipping by translation of the apex movement to edge movement ratio was for group1, controlled tipping to translation was for group2 and no significant different was between groups in both stages $\left(T_{0}-T_{1}\right)$ and $\left(T_{0}-T_{2}\right): p=0.111, p=0.93$. No significant difference was between stages $\left(\mathrm{T}_{0}-\mathrm{T}_{1}\right)$ and (T0-T2) in both groups (Figure 11, Table 7).

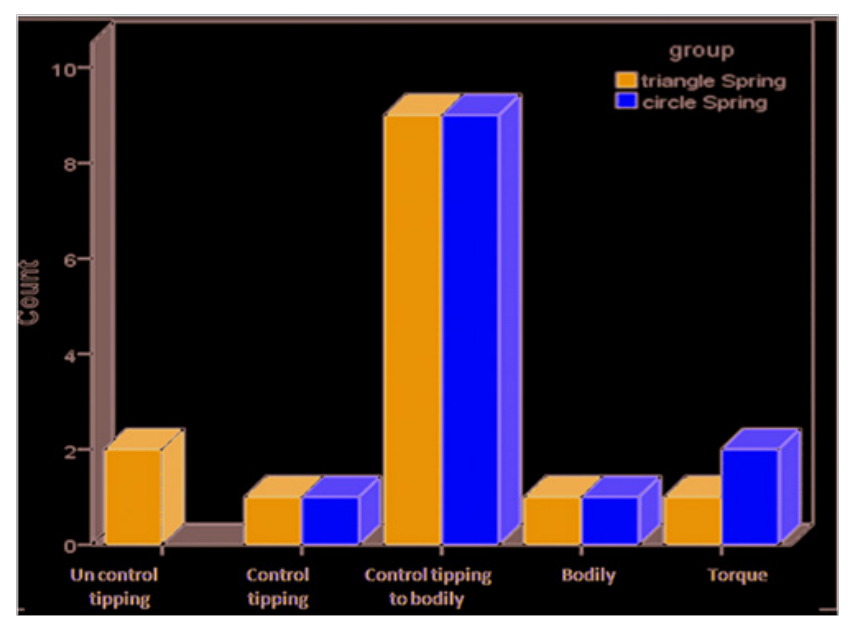

Figure 9 Type of movement of both groups at stage $\left(T_{0}-T_{1}\right)$.

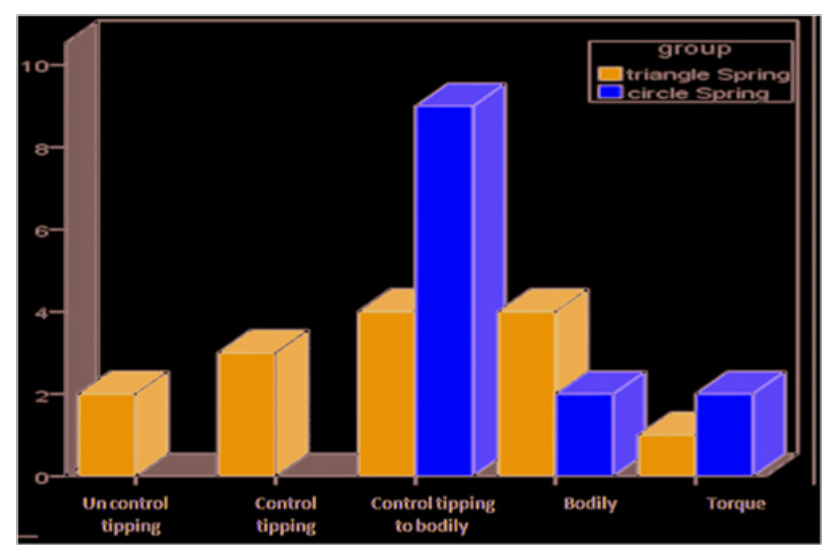

Figure 10 Type of movement of both groups at stage $\left(T_{0}-T_{2}\right)$.

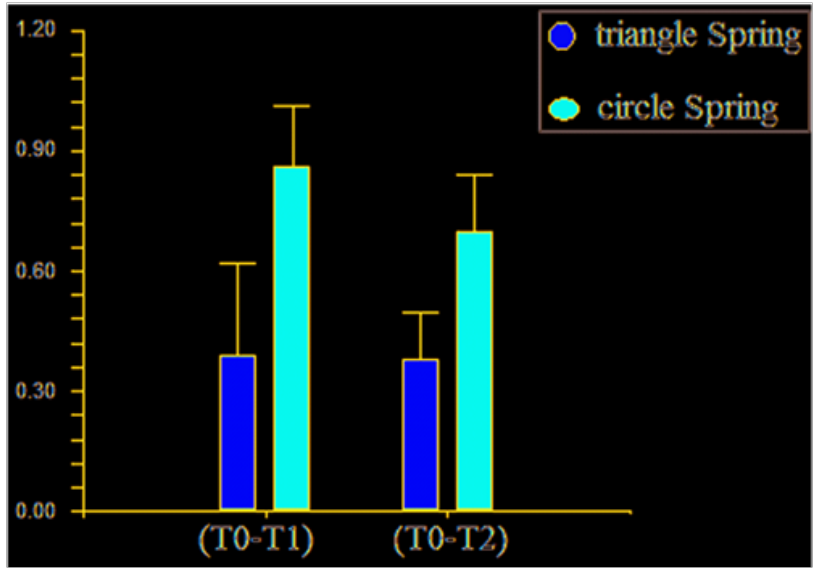

Figure I I Mean \& SD of movement type of both groups and two stages.

\section{Discussion}

Finite element study

Manhartsberger et al. ${ }^{28}$ suggest low load deflection Rate of spring for control of movement. Load deflection rate affected by wire length as loops, helixes and affected with memory alloys. ${ }^{1}$ The springs consisted of TMA alloy double loop-one helix had low load-deflection rate for two models. ${ }^{2}$ Load-deflection rate of TMA alloy was $26.315 \mathrm{~g} / \mathrm{mm}$ and $47.504 \mathrm{~g} / \mathrm{mm}$, for triangle and Circle forms respectively. Both of springs were considered lower than loaddeflection rate of PG spring $(100 \mathrm{~g} / \mathrm{mm})$, T loop $(55 \mathrm{~g} / \mathrm{mm})$, vertical loop $(114 \mathrm{~g} / \mathrm{mm})$, double vertical loop $(75 \mathrm{~g} / \mathrm{mm}) .{ }^{29}$ The optimal force of incisors' retraction is $100 \mathrm{~g} / \mathrm{cm} .{ }^{6,30}$ Therefore, the activation amount of TMA alloy triangle spring is $4 \mathrm{~mm}$, TMA alloy Circle spring is $2 \mathrm{~mm}$ (Table 1$) . \mathrm{Mc} / \mathrm{F}=8$ ratios will be achieved when power arm length was $8 \mathrm{~mm}$ comparison with $6-7 \mathrm{~mm}$ which gave $\mathrm{Mc} / \mathrm{F}$ ratio (6.7-7.2) (control tipping movement) according to FE analysis despite the vertical moment was added to a couple moment. ${ }^{12,15,16}$

\section{Clinical study}

In recommended system, the force vector applied at $8 \mathrm{~mm}$ above bracket's slot that produced a horizontal movement of edge and apex of upper incisors for group14.9 $\pm 2.3 \mathrm{~mm}, 1.7 \pm 1.6 \mathrm{~mm}$ respectively, and $4.6 \pm 1.9 \mathrm{~mm}, 2.4 \pm 1.1 \mathrm{~mm}$ for group 2 respectively. No significant difference was between groups. The speed of upper incisors retraction at group1 was better than group2. Maybe the reason is the deactivation of springs; the deactivation of triangle spring after $1 \mathrm{~mm}$ movement is $26.3 \mathrm{~g} / \mathrm{mm}$, and the remained force is $78 \mathrm{~g}$, which can move the incisors. While the deactivation of the circle spring after $1 \mathrm{~mm}$ movement is $47.5 \mathrm{~g} / \mathrm{mm}$ and the remained force is $47.5 \mathrm{~g}$ which is not suitable to move the incisors. Comparing to Dincer's results, when he applied $150 \mathrm{~g}$ at $9 \mathrm{~mm}$ for upper incisors retraction, and had noticed horizontal movement of root and edge $0.21 \pm 0.19 \mathrm{~mm}, 3.45 \pm 0.41 \mathrm{~mm}$ respectively (Figure 12). ${ }^{27}$

No extrusion movement of upper incisors (Table 4) resulted by paralleling the force vector to the main wire, ${ }^{31}$ in addition, the recommended system is the practical application of determinate force system which can easily discern, measure and evaluate the moments and force. ${ }^{23}$ The axis of upper incisors had changed about $-6.71 \pm 5.9$ degree for group 1, $-4.34 \pm 5.6$ degree for group 2, and no significant different was between groups $\mathrm{p}>0.05$ (Table 3 ). 
Table 3 Resulted of FEM at incisors

\begin{tabular}{|c|c|c|c|c|c|c|c|c|c|}
\hline \multicolumn{10}{|c|}{ Evaluation of Produced Moment at Incisors (Mf, Mc, Mv, Mc/F) } \\
\hline \multicolumn{10}{|c|}{6 mm Power Arm Height with Differential 2 mm between Power Arm and Miniscrew } \\
\hline$M_{N}-M f$ & $\begin{array}{l}M_{N} / M f \\
\text { Ratio }\end{array}$ & $\begin{array}{l}\mathbf{M}_{\mathbf{N}} / \mathbf{F z} \\
\text { Ratio }\end{array}$ & $M_{N=}(M c+M v)$ & Mv & $\mathbf{M c}(\mathbf{F d} * 8)$ & $\operatorname{Mf}(F d * 2)$ & $\mathbf{F z}(\mathbf{H})$ & $\mathbf{F y}(\mathbf{V})$ & $\mathbf{F}(\mathbf{g})$ \\
\hline 241.19 & 1.69 & 6.78 & 587.6 & 68. & 519.61 & 346.41 & 86.60 & 9.71 & 100 \\
\hline \multicolumn{10}{|c|}{7 mm Power Arm Height with Differential I mm between Power Arm and Miniscrew } \\
\hline 365.02 & 2.40 & 7.2 & 625.63 & 17.528 & 608.11 & 260.619 & 86.873 & 2.504 & 100 \\
\hline \multicolumn{10}{|c|}{$8 \mathrm{~mm}$ Power Arm Height with Differential $0 \mathrm{~mm}$ between Power Arm and Miniscrew } \\
\hline 523.69 & 4 & 8 & 698.25 & 0 & 698.25 & 174.56 & 87.281 & 0 & 100 \\
\hline
\end{tabular}

Table 4 Mean of vertical, horizontal and axis movement

\begin{tabular}{|c|c|c|c|c|c|c|}
\hline \multirow{2}{*}{ T0-T2 } & \multicolumn{2}{|c|}{ Group I (Triangle Spring) } & \multicolumn{2}{|c|}{ Group 2 (Circle Spring) } & \multirow{2}{*}{\multicolumn{2}{|c|}{$\begin{array}{l}\text { t-Test Independent } \\
\text { Sig Value }\end{array}$}} \\
\hline & Mean & S.D & Mean & S.D & & \\
\hline Apex I/Y(mm) & 1.7 & 1.6 & 2.4 & I.I & 0.55 & NS \\
\hline Edge $I / Y(m m)$ & 4.9 & 2.3 & 4.6 & 1.9 & 0.27 & NS \\
\hline Apex $\mathrm{I} / \mathrm{X}(\mathrm{mm})$ & -0.39 & 2.59 & 0.53 & 1.37 & 0.43 & NS \\
\hline Edge $\mathrm{I} / \mathrm{X}(\mathrm{mm})$ & 0.25 & 1.8 & 0.69 & I.I & 0.14 & NS \\
\hline IISpP( $\theta)$ & -6.71 & 5.9 & -4.34 & 5.6 & 0.71 & NS \\
\hline
\end{tabular}

Table 5 Values of rotation center.

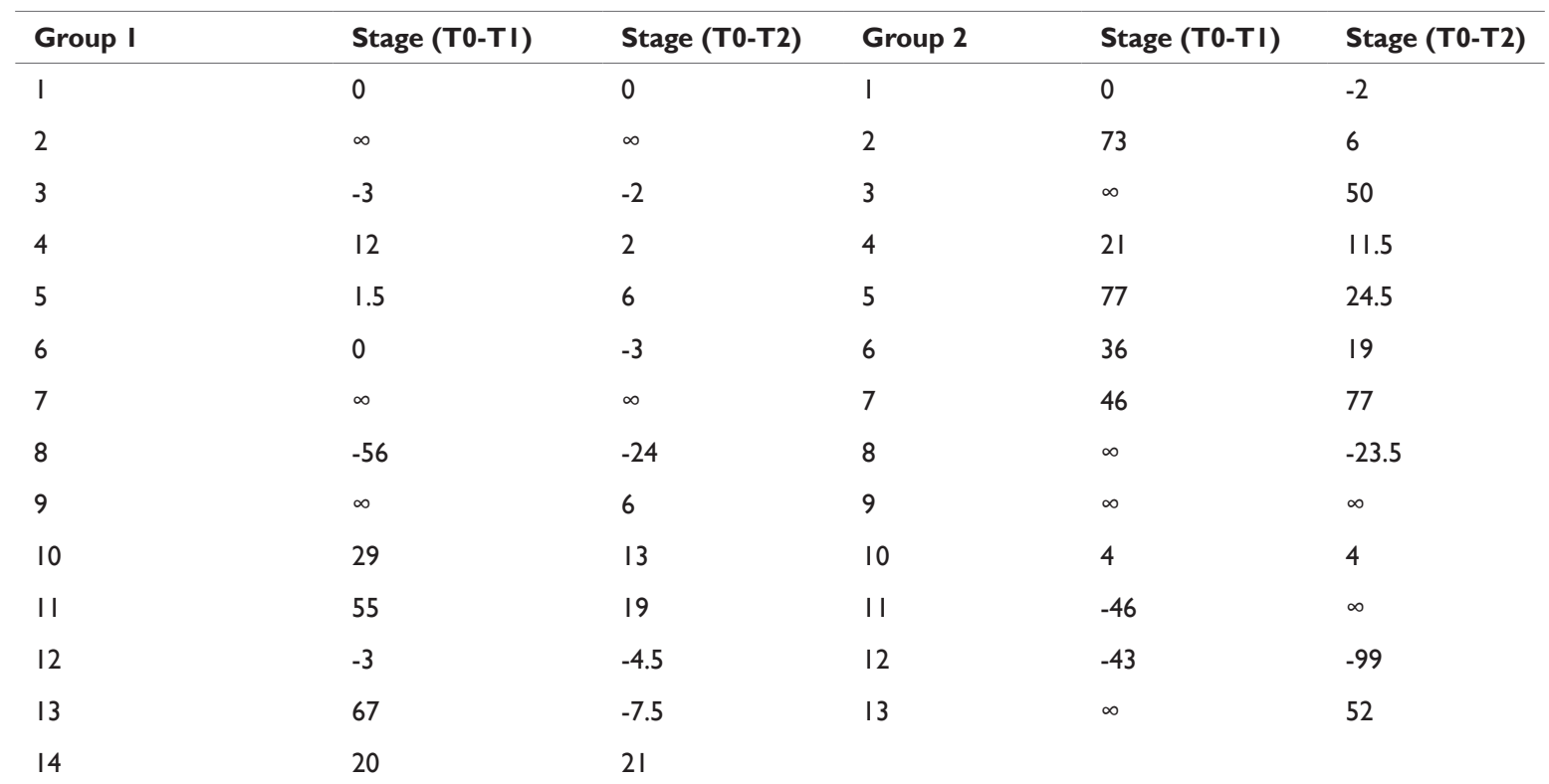

Table 6 Rotation of center of groups

\begin{tabular}{|c|c|c|c|c|c|c|c|}
\hline & Groups & $\mathbf{N}$ & Mean & SD & SE & $\begin{array}{l}\text { t-Test of } \\
\text { Sig Value }\end{array}$ & endent Sample \\
\hline \multirow{2}{*}{$\begin{array}{l}\text { Center Rotation } \\
\text { (T0-TI) }\end{array}$} & Triangle Spring & 14 & 31.89 & 50.23 & 13.42 & \multirow{2}{*}{.403} & \multirow{2}{*}{ NS. } \\
\hline & Circle Spring & 13 & 50.15 & 61.20 & 16.97 & & \\
\hline \multirow[b]{2}{*}{ Center Rotation(T0-T2) } & Triangle Spring & 14 & 7.50 & 15.12 & $4.04 I$ & \multirow[b]{2}{*}{.222} & \multirow[b]{2}{*}{ NS. } \\
\hline & Circle Spring & 13 & 28.11 & 59.59 & 16.52 & & \\
\hline $\begin{array}{l}\text { Paired Samples Test } \\
\text { (T0-TI) - (T0-T2) }\end{array}$ & Sig & & .044 & & & & \\
\hline
\end{tabular}

Citation: Suleiman MAL, Baba F, Suliman A, et al. Clinical evaluation of upper incisors retraction frictionless system depending on mini-screw.J Dent Health Oral Disord Ther. 20I4; I (2):30-37. DOI: 10.15406/jdhodt.2014.01.00009 
Table 7 Type of movement of groups

\begin{tabular}{|c|c|c|c|c|c|c|c|}
\hline & Group & $\mathbf{N}$ & Mean & SD & SE & $\begin{array}{l}\text { t-test for Equality of Means Indepen } \\
\text { Sample }\end{array}$ & ent \\
\hline \multirow[t]{2}{*}{ Apex.M(T0-TI)\Edge.M(T0-TI) } & Triangle Spring & 14 & .390 & .864 & .230 & $\begin{array}{l}\text { Controlled tipping partly by } \\
\text { translation }\end{array}$ & \multirow[t]{2}{*}{ N S.I I I } \\
\hline & Circle Spring & 13 & .857 & .562 & .155 & controlled tipping to translation & \\
\hline \multirow{2}{*}{ Apex.M(T0-T2)\Edge.M(T0-T2) } & Triangle Spring & 14 & .380 & .428 & .114 & Controlled tipping partly by translation & NS \\
\hline & Circle Spring & 13 & .697 & .514 & .142 & controlled tipping to translation & .093 \\
\hline Paired Samples Test (T0-T1) - (T0-T2) & NS. & & .475 & & & & \\
\hline
\end{tabular}

\section{The center of Rotation}

The translation movement has achieved when the center of rotation is at infinity. ${ }^{32}$ Siatkowski ${ }^{11}$ demonstrated that the translation movement can be achieved by both inclination of incisors $58^{\circ}$ at Op, and $\mathrm{Mc} / \mathrm{F}=8 \mathrm{~mm}$ 4ratio. $\mathrm{FE}$ analysis of recommended system showed that $8 \mathrm{~mm}$ power arm height achieved $\mathrm{Mc} / \mathrm{f}=8 \mathrm{~mm}$, and the inclination of incisors of group 1 (triangle spring) was $61.7^{\circ} \pm 5.0^{\circ}$ and $62.7^{\circ} \pm 4.2^{\circ}$ in Group 2 (circle spring) (Figure 13).
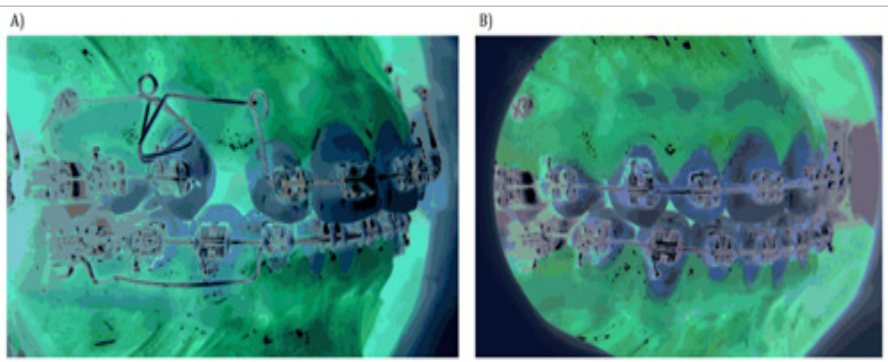

Figure 12 A) Start of retraction (case I of triangle spring group). (B) The finishing (case I of triangle spring group).
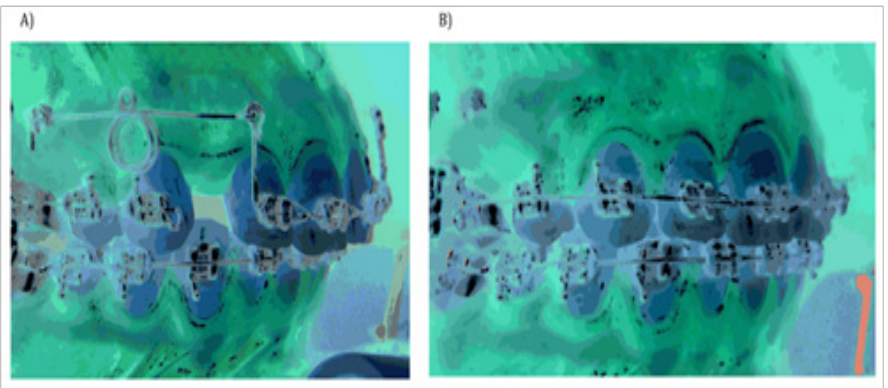

Figure I 3 A) Start of retraction (case 2 of circle spring group). B) The finishing (case 2 of circle spring group).

The results showed that center of rotation was at $31.8 \pm 50.2$, $50.1 \pm 61.2$ Group $1 \&$ Group 2 respectively for stage one (T0-T1) and no significant difference was between groups $\mathrm{P}=0.403$.

Various positions of the center of rotation were in every group (infinity, positive and negative values). According to Manhartsberger et $a{ }^{28} \&$ Turk et ${ }^{21} .^{33}$ the reasons maybe were the individual difference between patients such as root length, alveolar bone, initially inclination of incisors and PDL morphology. The results of the rotation center were $7.5 \pm 15.1,28.1 \pm 59.5$ at Group $1 \&$ Group
2 for retraction stage (T0-T2). No different significant was between groups $p=.222$. Fallback of center rotation could be resulted because the limiting factors in orthodontic retraction such as palatal cortical bone and width of alveolar bone, ${ }^{33}$ or the retraction distance. ${ }^{34}$

\section{Type of Movement}

Jung and $\mathrm{Kim}^{35}$ recommend $10 \mathrm{~mm}$ power arm height to produce the controlling movement retraction. Sia et al. ${ }^{18}$ recommended $8-10 \mathrm{~mm}$ power arm height to achieve torque movement, $6-8 \mathrm{~mm}$ power arm height to have controlled tipping movement.

Applying force at $8 \mathrm{~mm}$ power arm height produced equivalent moment 523g.mm, force moment $174 \mathrm{~g} . \mathrm{mm}$ and force at root apex $65.3 \mathrm{~g}$ according to finite element analysis of recommended system. Using the formula of the apex movement to edge movement ratio, movement type of group 1 was uncontrolled, controlled tipping to bodily movement $(0.39 \pm 086)$, beyond in group 2 was controlled tipping to bodily movement $(0.85 \pm 0.56)$ during two months of retraction (T0T1). No significant difference was between groups $p=0.111$. The ratio of the completed period of retraction (T0-T2) in group 1 and group 2 were $0.38 \pm 0.42$ and $0.69 \pm 0.51$, respectively (controlled tipping to bodily movement), no significant difference was between groups $p=0.093$. Upadhyay et al. ${ }^{22}$ had $0.33 \pm 0.20$ Ratio (partly controlled tipping by translation) at skeletal anchorage group $-0.15 \pm 0.56$ (uncontrolled tipping) at traditional anchorage group.

In this study, achieved $8 \mathrm{~mm}$ power arm height $(\mathrm{Mc} / \mathrm{Mf}=4)$ Ratio and $\mathrm{Mc} / \mathrm{f}=8 \mathrm{~mm}$ in both groups and stable $\mathrm{M} / \mathrm{F}$ Ratio (FE analysis), but the accomplished movement was no translation movement. The movement types changed between cases (Uncontrolled tipping, Controlled tipping, controlled tipping to bodily, Bodily, and Torque). In spite that all conditions of affective factors were convergent, the center of resistance could be affected by root length, alveolar bone height, incisors inclination and number of motion teeth. ${ }^{27,36,37}$ The Cre moved apically $1.3 \mathrm{~mm}$ when root length increased of 50 per cent and the Cre moved $4 \mathrm{~mm}$ apically when alveolar bone height decreased of 50 percent. ${ }^{38}$ The inclination of incisors is affected by distance between Cre and force vector. ${ }^{12,16}$

Nevertheless, do root length, alveolar bone height and inclination of incisors axis have influence at movement types only?

The Two sisters of subjects, one had controlled tipping movement, and the other had controlled tipping to bodily. In addition, two brothers (male - female) one had bodily movement, and the second had torque movement. The opinions which emphasize that mechanical properties of PDL, bone elasticity, bone-root anatomy are affective factors of 
movement type considered ${ }^{36,38}$ and the treatment mechanics would changed to obtain proposed incisors retraction. ${ }^{38}$

\section{Conclusion}

1. The suggested frictionless retraction system produce good control of the upper incisor movement.

2. No significant difference between group 1 and group 2 in the place of center of rotation.

3. No significant difference between group 1 and group 2 in speed of retraction.

\section{Acknowledgments}

None.

\section{Conflict of interest}

The author declares that there is no conflict of interest.

\section{References}

1. Burstone CJ. Application of bioengineering to clinical orthodontics. In: Graber TM, Vanarsdall RL, editors. Orthodontics: Current Principles and techniques. Mosby, St Louis;2005:293-330.

2. Nanda R. Biomechanics and Esthetic Strategies in Clinical Orthodontics. Elsevier Saunders, St. Louis;2005:194-210.

3. Smith RJ, Burstone CJ. Mechanics of tooth movement. Am J Orthod 1984;85(4):294-307.

4. Staggers JA, Germane N. Clinical consideration in the use of retraction mechanics. J Clin Orthod. 1991;25(6):364-369.

5. Reynders R, Ronchi L, Bipat S. Mini-implants in orthodontics: a systematic review of the literature. Am J Orthod Dentofacial Orthop. 2009;135(5):564.e1-19.

6. Park HS, Kwon OW, Sung JH. Microscrew implant anchorage sliding mechanics. World J Orthod. 2005;6(3):265-274.

7. Chung KR, Kim SH, Kook YA. The C-orthodontic micro-implant. J Clin Orthod. 2004;38(9):478-486.

8. Erverdi N, Keles A, Nanda R. Orthodontic Anchorage and Skeletal Implants. In: Nanda R, editors. Biomechanics and Esthetic Strategies in Clinical Orthodontics: Elsevier Inc;2005:278-293.

9. De Pauw GA, Dermaut L, De Bruym H, et al. Stability of Implants As Anchorage for orthopedic traction. Angle Orthod. 1999;69(5):401-407.

10. Yoshida N, Koga Y, Mimaki N, et al. In vivo determination of the centers of resistance of Maxillary anterior teeth Subjected to retraction forces. Eur J Orthod. 2001;23(5):529-534.

11. Siatkowski RE. Force system analysis of v-bend sliding mechanics. $J$ Clin Orthod. 1994;28(9):539-546.

12. Melsen B, Fotis V, Burstone CJ. Vertical force consideration in differential space closure. J Clin Orthod. 1990;24(11):678-683.

13. Sia S, Koga Y, Yoshida N. Determining the center of resistance of maxillary anterior teeth subjected to retraction force in sliding mechanics, an in vivo study. Angle Orthod. 2007;77(6):999-1003.

14. Vanden Bulcke MM, Burstone CJ, Sachdeva RC, et al. Location of centers of resistance for anterior teeth during retraction using the laser reflection technique. Am J Orthod Dentofacial Orthop. 1987;91(5):375-384.

15. Gjessing P. A universal retraction spring. $J$ Clin Orthod. 1994;18(4):222-242.
16. Gjessing P. Controlled retraction of maxillary incisors. Am J Orthod Dentofacial Orthop. 1992;101(2):120-131.

17. Fisher JC, Burton J. Incisor translation and inclination using miniscrew anchorage and the edgewise appliance.J Clin Orthod.2008;42(4):210-214.

18. Sia S, Shibazaki T, Koga Y, et al. Experimental determination of optimal force system required for control of anterior tooth movement in sliding mechanics. Am J Orthod Dentofacial Orthop. 2009;135(1):36-41.

19. Chung KR, Cho JH, Kim SH, et al. Unusual extraction treatment in Class II division 1 using C-orthodontic mini-implants. Angle Orthod. 2007;77(1):155-166.

20. Chung KR, Nelson G, Kim SH, et al. Severe bidentoalveolar protrusion treated with orthodontics microimplant -dependent en-mass retraction. Am J Orthod Dentofacial Orthop. 2007;132(1):105-115.

21. Park YC, Chu JH, Choi YJ, et al. Extraction Space Closure with Vacuum-Formed Splints and Miniscrew Anchorage. J Clin Orthod. 2005;39(2):76-79.

22. Upadhyay M, Yadav S, Nagaraj K, et al. Treatment effects of mini-implants for en-mass retraction of anterior teeth in bialveolar dental protrusion patients: a randomized controlled trail. Am J Orthod Dentofacial Orthop. 2008;134(1):18-29.

23. Choy K, Pae EK, Kim KH, et al. Controlled Space Closure with a Statically Determinate Retraction System. Angle Orthod. 2002;72(3):191-198.

24. Park YC, Choi YJ, Choi NC, et al. Esthetic segmental retraction of maxillary anterior teeth with a palatal appliance and orthodontic miniimplants. Am J Orthod Dentofacial Orthop. 2007;131(4):537-544.

25. Sung JH, Kyung Hm, Park HS, et al. Microimplant in orthodontics. Dentos, Inc. 2006.

26. Poggio PM, Incorvati C, Velo S, et al. "Safe Zones": a guide for miniscrew positioning in the maxillary and mandibular arch. Angle Orthod. 2006;76(2):191-197.

27. Dincer M, Gulsen A, Yurk T. The Retraction of upper incisors with the PG retraction system. Eur J Orthod. 2000;22(1):33-41.

28. Manhartsberger C, Morton JY, Burstone CJ. Space closure in adult patients using the segmented arch technique. Angle Orthod. 1989;59(3):205-210.

29. Ferreira Mdo A, de Oliveira FT, lgnacio SA, et al. Experiment force definition system for a new orthodontic retraction spring. Angle Orthod. 2005;75(3):368-377.

30. Ricketts MR, Bench RW, Gugino CF, et al. Bioprogressive Therapy. JPO. Inc. 1987.

31. Bae SM, Park HS, Kyung HM, et al. Clinical application of micro-implant anchorage. J Clin Orthod. 2002;36(5):298-302.

32. Christiansen RL, Burstone CJ. Centers of rotation within the periodontal space. Am J Orthod. 1969;55(4):353-369.

33. Turk T, Elekdaq-Turk S, Dincer M. Clinical evaluation of the center of resistance of the upper incisors during retraction. Eur $J$ Orthod. 2005;27(2):196-201.

34. Horiuchi A, Hotokezaka H, Kobayashi K. Correlation between cortical plate proximity and apical root resorption. Am J Orthod Dentofacial Orthop. 1998;114(3):311-318.

35. Jung MH, Kim TW. Biomechanical Considerations in Treatment with Miniscrew Anchorage. Part 1 The Sagittal Plane. J Clin Orthod. 2008;42(2):79-83.

36. Tanne K, Nagataki T, Inoue $Y$, et al. Patterns of initial tooth displacements associated with various root lengths and alveolar bone heights. Am J Orthod Dentofacial Orthop. 1991;100(1):66-71. 
37. Reimann S, Keilig L, Jager A, et al. Biomechanical finite-elemen investigation of the position of the center resistance of upper incisors. Eur J Orthod. 2007;29(3):219-224.
38. Edwards JG. A Study of anterior portion of the palate as it relates to orthodontic therapy. Am J Orthod. 1976;69(3):249-273. 